\title{
Response to Commentaries on The Management of Narcissistic Vulnerability: Three Case Studies Guided by Stephen Mitchell's Integrated Treatment Model
}

\section{A Personal Perspective on the Treatment of Three Cases of Narcissistic Vulnerability}

\author{
ROBERT W. RIORDAN ${ }^{\mathrm{a}, \mathrm{b}}$ \\ ${ }^{\mathrm{a}}$ Graduate School of Applied and Professional Psychology, Rutgers University \\ b \\ Correspondence concerning this article should be addressed to Robert W. Riordan, Graduate School of Applied \\ and Professional Psychology, Rutgers University, 152 Frelinghuysen Road, Piscataway, NJ 08854 \\ Email: riordan333@hotmail.com
}

\begin{abstract}
This article is a response to the commentaries of Nancy McWilliams (2012) and Kenneth Levy (2012) concerning my treatment of three patients—Alex, Brian, and Candace—whose presenting difficulties included a narcissistic personality disturbance and who were treated using Mitchell's (1988) integrated treatment model. In addition to responding to particular points raised by McWilliams' more "artistic" and Levy's more "scientific" perspectives, I provide a more personal context and view of my experience in providing therapy to these three patients.
\end{abstract}

Key words: narcissistic personality disturbance; narcissistic personality disorder; narcissism; Kernberg; Kohut; Mitchell's integrated treatment model; case study; clinical case study

\section{INTRODUCTION}

In my target article (Riordan, 2012), I present case studies of "Alex," "Brian," and "Candace," three individuals who presented to long-term therapy with a narcissistic personality disturbance. I treated these individuals in accordance with Stephen Mitchell's (1988) theory of narcissistic illusion, which integrates Kernberg's (e.g., 1984) view of narcissism as a defensive phenomenon and Kohut's (e.g., 1984) view of narcissism as a growth-enhancing opportunity. Detailed qualitative outcome information, and limited quantitative outcome data, indicated some success, with psychological growth noted in each of the patients.

In commenting on my article, Nancy McWilliams (2012) and Kenneth Levy (2012) take different but complementary perspectives in critically evaluating the nature and implications of my work. Below I briefly comment on each commentary and then present some observations to expand the reader's understanding of what I individually brought to the treatment of Alex, Brian, and Candace. 


\section{MCWILLIAMS ON THE "ARTISTIC" ASPECTS OF THERAPY AND THE LARGER CULTURAL CONTEXT OF NARCISSISTIC THEMES}

McWilliams (2012) offered comments on my work from a viewpoint that seems common to her writings (e.g., McWilliams, 2004); namely, she views the clinician's humanity as an integral part of the therapeutic enterprise. In this context, McWilliams considered, among other things, the "less specifiable, more artistic elements of the psychotherapy process" (2012, p. 203) with regard to my treatment of three individuals struggling with narcissistic vulnerability. This includes subjectively inferred aspects of my therapeutic style, such as prosody (tone), as well as the role of play in reducing "the suffering of clients who rely on narcissistic defenses to compensate for a fragile, erratic, or unrealistic sense of self-esteem" (2012, p. 203).

Through example, be it in her writings or teaching, McWilliams has shown her readers and students that it takes intellect and self-awareness to step beyond the safe shores of concrete thinking in order to address the messier questions of our profession. There is nothing messier than the patient when he is fully seen as a person in struggle and not as simply a diagnostic category. Guided by McWilliams' work, I feel that the benefit of my project lies in the fact that I learned that my patients, while all struggling with narcissistic vulnerability, were very different people. Each had unique aspirations and desires, as well as unique capacities and deficits. In fact, McWilliams' expansive thinking has prompted me to consider a new question with which I am currently grappling: were these three patients so different from one another that there exists the possibility that their underlying narcissistic pathology differed more so than I had originally contemplated? For instance, could Alex's grandiosity, designed to endear him to others, be a grandiosity that is effectively different from Brian’s grandiosity, designed to ensure some measure of self-esteem by degrading others? Does such a distinction matter in terms of the treatment of these patients? This is perhaps not an original question; however, I feel that it merits further attention as we attempt to figure out how to best connect with our patients.

This question aside, each patient sought contact and was ultimately changed by a successful connection with me. I thank McWilliams for reminding me it is a worthy pursuit to consider all factors that bear positively or negatively on the ability to attain such a connection.

McWilliams also presents a fascinating discussion of the cultural contexts relevant to understanding the reported increase in narcissistic problems in contemporary patients. I found this exploration a most valuable contribution for placing my own personal experiences (as discussed below) and my clinical work in larger context.

\section{LEVY ON THE "SCIENTIFIC" ASPECTS OF THERAPY}

In contrast to McWilliams, Levy (2012) focuses on conceptual and methodological issues in the design of my case studies and presents technical advances in Kernberg's approach that are designed to meet the concerns that I raised about this model. I welcome Levy's thorough and wide-reaching comments concerning the design of my project and the ways in which such designs could be improved in the future. As anyone who has undertaken a project of this nature will know, there were numerous choices made during the course of research, some made out of necessity and others attributable to error. I feel as though Levy did me and the reader a great 
service by sharing his wisdom about research design and his reflections on both the merits and shortcomings of my methodology.

One of the faults of my project, as reflected in Levy's comments, is my failure to make it clear that I was not attempting to discount the theories of Kernberg or Kohut. Rather, I am an advocate of broadening the discussion. As Levy notes, the reality is that the theories of Kernberg, Kohut and Mitchell overlap to a certain degree. Since this is true, it seems best for all if room is made for a thorough consideration of the merits of each. Broadening the discussion can allow clinicians to find an approach that speaks to their individual abilities and the way in which they best conceptualize pathology and its treatment.

Levy raises two points that particularly sparked my interest. First, he notes that the patient with narcissistic vulnerability experiences an oscillation between his grandiose and depleted selves. The patients in my project were, for the sake of the study, noted as being predominantly grandiose or depleted (or grandiose and depleted in equal measure); these designations are, of course, a fiction. It is apparent to most clinicians that individuals with narcissistic vulnerability struggle simultaneously with both grandiosity and the underlying depression. However, Levy's use of the word “oscillation,” (2012, p. 217), a concept that he presumably borrowed from his work in Transference-Focused Psychotherapy (TFP; Levy et al., 2006), is fascinating; it points to the issue that one patient may present differently week to week and, as a result, that individual may be open to different interventions at different times. I have questioned whether the patient's underlying narcissistic pathology differs from person to person, and Levy asserts that the presentation of such narcissism may be oscillating from session to session. If we are both correct, the clinician is indeed in for a challenge.

In addition, Levy discusses an approach for dealing with the lack of empirically supported treatments for Narcissistic Personality Disorder (NPD) based on a dearth of randomized clinical trials for this disorder. He proposes employing empirically supported treatments for the near-neighbor disorder of Borderline Personality Disorder (BPD) in an effort to take an evidence-based approach to NPD; and, he makes an argument for utilizing his own TFP for this purpose. In his argument, Levy's suggests that NPD is similar to BPD in terms of the patient's “identity, defenses and social reality testing” (2012, p. 223). On first impression, I think that it is a large leap to categorically place those who struggle with NPD and those who struggle with BPD next to one another on a continuum. The degree of identity disturbance, the reliance on the use of splitting and, above all, the soundness of reality testing can vary greatly among patients struggling with narcissistic issues. In fact, I wonder if some individuals with significant narcissistic vulnerability may not suffer from any marked identity disturbance, may not rely on splitting as a defense, and/or may have intact reality testing.

Here, I imagine that Levy would argue that these individuals are not then on the narcissistic spectrum or may not have Narcissistic Personality Disorder per se. Granted, I have not treated the severely disturbed narcissistic patients to which Levy refers. Would I have a different view of this juxtaposition if I had treated this population? Or are narcissistic individuals labeled "severely disturbed" because that is how a theorist initially conceptualized them and where he placed them on a broad continuum of psychopathology? I will indeed review the sources provide by Levy as these matters seems to be at the heart of whether one can properly 
analogize the applicability of TFP to narcissistic pathology based on the view that NPD and BPD are largely similar. I thank Levy for drawing my attention to several new areas to consider.

\section{A PERSONAL PERSPECTIVE ON CONDUCTING THERAPY WITH ALEX, BRIAN, AND CANDACE}

To expand the reader's understanding of the personal dimension of my work with Alex, Brian, and Candace, I would like to add some comments below linking experiences in my own personal therapy to my work with the three patients. I note that this disclosure is consistent with the movement of relational psychoanalysis, which Mitchell (1988) spearheaded in his rejection of the notion of the therapist's neutrality (see below), and the "two-person" model of psychoanalysis versus the "one-person" intrapsychic view of traditional psychoanalysis (Messer, 2011).

There was a time in my life when a public discussion—like McWilliams' and Levy's commentaries - that drew attention to the shortcomings of my work would have been very hard for me to tolerate. Today, however, I am genuinely appreciative that there are such scholars who are willing to share with me their time and expertise.

Following several years of individual psychotherapy, I am no longer highly vulnerable to the self-esteem injuries that once plagued me. I am thankful that my paper, one individual's attempt to make a contribution to a difficult discussion, reflects my genuine interests. The subject that first captured my (self-focused) attention was how did a 30-year-old corporate lawyer, with all of the external markers of success, emerge from psychotherapy five years later as a man who understood his personality dynamics and appreciated how such dynamics were contributing to his profound dissatisfaction?

In the years that I was in treatment, I made significant, albeit limited, changes. I went from a crippling concern about the opinions of others to an understanding that I am, more or less, just another guy struggling through life to do his best. I went from a man who harbored fantasies of grandiosity to a man who, more and more often, is content to join the crowd. And, I went from a man who had entered a profession that reflected none of his interests or values to a man who was able to appreciate that his talents lie in a field where no practitioner is overvalued or overpaid. Therapy did not fundamentally alter my personality; rather, I grew aware of the lens through which I viewed the world, and I now continually work to gain "increased control over [my] worst inclinations" (McWilliams, 2012, p. 205). I acknowledged my narcissistic worldview, and I work on a daily basis to renounce it. I may not have experienced in treatment an overhaul of my personality structure; yet, therapy was enough to liberate me from chronic dissatisfaction and self-imposed social isolation.

What exactly happened in that therapy room over the course of five years to create such movement? 


\section{MY CHOICE OF MITCHELL'S MODEL}

Based on my experience in therapy and my wide-ranging review of the theoretical literature on psychotherapy with individuals with a narcissistic personality disturbance, when I ultimately came across the work of Mitchell, I encountered a theorist who "spoke" in a particularly helpful way to my experience as a clinician. I found a great deal of comfort in the approach suggested by Mitchell since it allowed me to free myself from the many "shoulds" that I had been taught throughout my training. I particularly liked the fact that Mitchell's model is less structured and allows the therapist to join the patient in play. I felt as though I was entirely myself in the room, and this was crucial, as the treatment of individuals with narcissistic vulnerability can leave the clinician feeling very exposed. If I am exposed, I want what is revealed to be entirely me and not a set of techniques. To this end, I feel as though conducting therapy with Alex, Brian, and Candace allowed me to get a better sense of who I am as a clinician.

\section{THE OPPORTUNITY TO INTENSIVELY REVIEW DETAILED SESSION NOTES}

The discipline of the systematic case studies that I conducted with Alex, Brian, and Candace provided me the opportunity to repeatedly and intensively review my detailed session notes, allowing me to consider the actual words that I spoke to each of these clients. In a profession where the words spoken by the clinician to the patient are critical, I was disappointed that the leading clinical figures in this arena rarely, if ever, address what the practitioner is actually supposed to say in session (other than to suggest that interventions should be "carefully worded"). These case studies afforded me the opportunity to consider exactly how a clinician verbally approaches the problem of narcissistic vulnerability. Although these three therapies are unique and can never be recreated by another clinician, I believe that they provide a window into Mitchell's approach and how such an approach may look in practice.

\section{THE THERAPEUTIC RELATIONSHIPS WITH THE THREE CLIENTS}

The empirical literature affirms the importance of the therapeutic relationship in facilitating positive outcome in psychotherapy (e.g., Blatt \& Zuroff, 2005; Norcross, 2011). In line with this, I believe that a crucial element in my work with Alex, Brian, and Candace was my ability to develop genuine therapeutic relationships with all three patients. Our respective relationships changed over the course of the treatment, and, at the end of each therapy, the patient had connected to me in a way that I believe he or she had formerly been unable to do. Not only did the words I spoke to them matter; but also, and perhaps more consequentially, the intent behind the words mattered. As McWilliams notes, one of the most critical aspects of facilitating change in a narcissistic patient may be the demonstration of respect for the patient.

I ultimately favored Mitchells’ conceptualization because, while honoring the contributions of Kernberg and Kohut, Mitchell helps the therapist to understand what the patient is trying to communicate. Why is the patient in session (and therefore looking to connect in some 
form) and, at the same time, engaging in behavior that seems to repel any sense of connection? Such behavior is indeed difficult for the therapist to experience, yet it is also functional. The patient is telling the therapist that the patient matters (for reasons that the patient values). In the absence of such an expression, the patient may not be able to proceed with the relationship because he does not understand that there exist alternative ways by which human connectedness is founded and maintained.

As the therapist, I had to figure out how to respect such efforts, for they may well be the patient's best efforts. In this light, I had to move beyond seeing the patient struggling with narcissistic vulnerability as someone who is just frustratingly grandiose. Rather, I strove to appreciate that the individual patient was using his or her best efforts to grow toward a warm and dependable light which is repeatedly moved (by his own grandiose strivings) just beyond the patient's reach.

The treatment of the patient with narcissistic vulnerability is indeed challenging. It is not likely that change will be swift or complete. The narcissistic condition is ubiquitous, and it is debilitating. However, as McWilliams quoting Kernberg notes, it is an increasingly important endeavor: "the value of even small improvements for a narcissistically obsessed client can be incalculable" (2012, p. 206).

\section{RECOGNIZING THE INDIVIDUALITY OF EACH PATIENT}

What exactly happens in the therapy room to create change in an individual struggling with narcissistic vulnerability?

Based on my own experience to date as a patient and as a therapist, I believe that the answer to this difficult question does not lie in the creation of a treatment protocol that is broadly applied to all patients struggling with narcissistic vulnerability. In the literature, we seem to have hurried past the important task of getting to fully know the narcissistic individual and his or her interior life; and, we have jumped to the creation of interventions based on a fixed understanding of what narcissism is and what it takes to ameliorate it. Yes, we can tick boxes and agree that narcissistic patients are grandiose, suffer certain preoccupations, etc. However, I do not think that my improvement through my own psychotherapy was the result of a set of carefully followed interventions. It was the result of the relationship that I developed with the therapist and the fact that, in the context of this relationship, I was seen in a way that I may never have been seen before in my entire life.

Furthermore, I am still not convinced that Alex, Brian and Candace each shared the exact same type of narcissistic pathology. As individuals, they each were seeking to communicate a worth that would connect them with their unique notion of caregiving. To this end, their struggle differed. Did the pathology underlying this struggle differ in some measure as well? I believe that my ability to see each patient as an individual first will best enable me to respond to this question.

In any event, it is this lack of sameness in these patients that should make the treatment of this population an energizing endeavor. Our broad understanding of personality dynamics can 
help us navigate the early sessions with a new patient, but, in time, the patients are going to show us their individuality. Once this individuality emerges, we need to rely on our humanity and our understanding of our own personality dynamics in order to navigate a relationship that is utterly unique to that therapy dyad.

\section{THE FACTORS UNDERLYING A SUCCESSFUL HEALING RELATIONSHIP}

In my view, my ability to successfully engage in a healing relationship with Alex, Brian, and Candace relied on three factors. First, I did not assume that all patients struggling with narcissistic vulnerability share the exact same broken internal structures or developmental arrest. Such a stance is too simplistic. I believe that there is more than one narrow path to the creation of narcissistic pathology, and, further, I question whether such pathology may be best conceptualized as a phenomenon that exists solely in the interpersonal realm. In this context, Mitchell's approach appealed to me because it urged me as the clinician to pay attention to the patient in the moment in the context of a relationship. Mitchell guided me to not approach the patients armed with a belief in the intractability of the narcissistic condition or with a set of techniques to be used in sequence. Rather, his writings encouraged me to focus my efforts on inthe-moment communication in the context of a growing relationship. He urged me to be human and to use such humanity to enliven the patient.

Like Mitchell, I concluded, based on my clinical experience with Alex, Brian, and Candace, that therapeutic neutrality is a fiction. Thus, second, I believed that the individual personality of the individual therapist must be considered as it relates to therapeutic success with a narcissistically disturbed patient population. Be it my ability to play or my ability to tolerate devaluation (or my tone, professional demeanor, facial expressions, etc.), I needed to spend time thinking about my own therapist variables and their impact on the specific treatment of a specific patient.

All graduate students are told that it is important to "know oneself" so that one's personal issues do not color one's therapeutic abilities and the therapeutic relationship. While I agree that all graduate students of clinical psychology should be in therapy, what I found particularly important for me to reflect upon was what it is like for a patient to actually sit in a room with me. What is it like to look at my face for 50 minutes? To hear my voice? To gauge my reaction to the disclosure of secrets?

Consider, for instance, the fact that I am a tall man with broad shoulders. I have come to believe through my clinical experiences to date that many of my patients want to climb into my lap and be held by me. Others want me to accompany them to the playground and to act as an older brother when the kids start to play rough with them. Still others want to punch me for literally taking up too much room in this world. My ability to be an effective therapist rests in part on my understanding of these transferences but also my comfort with it. My understanding of the role of my stature and its impact in the therapy room allows the patient to fully use me in service of his growth. 
In terms of the treatment of the individual with narcissistic disturbance, I believe that factors such as professional demeanor are crucial to treatment success. Many patients struggling with narcissistic vulnerability are counterdependent, and they want to be in control of the moment that they reach out for connection. In my view, a therapist who is overtly empathic or overly solicitous at the outset of treatment may scare such a patient out of the room. The clinician who may otherwise have established a lasting relationship with the patient may never be afforded the chance to do so if this one variable goes unexamined.

Third, in my experience the role of respect cannot be underestimated when sitting in a room with a patient struggling with narcissistic vulnerability. If I had to identify the one thing that helped me to stay engaged in my own treatment for five years, it would be my therapist's respect for my efforts. Respect can still exist when a therapist is confronting a patient or coaxing him into play. My therapist respected where I was when I entered the treatment room, what I was trying to do each week in the room, and, above all, what I ultimately craved by coming to the room. I would be surprised if my therapist conceptualized me as someone with a misshapen superego. Rather, I feel as though I was seen as a person who did not understand that I did not need special credentials to connect with or to make an impact on another person. I felt that my efforts to connect, however impaired, were respected.

In the end, I believe that we are all working toward the goal of better conceptualizing narcissistic pathology and finding ways to be useful to the patient as he or she struggles to connect. I feel gratified that my project has been useful in part as it has helped to stimulate the continuing discussion about how to reach this important goal.

\section{REFERENCES}

Blatt, S. J., \& Zuroff, D. C. (2005). Empirical evaluation of the assumptions in identifying evidence based treatments in mental health. Clinical Psychology Review, 25, 459-486.

Kernberg, O.F. (1984). Severe personality disorders: Psychotherapeutic strategies. New Haven, CT: Yale University Press.

Kohut, H. (1984). How does analysis cure? Chicago: University of Chicago Press.

Levy, K. N., Meehan, K. B., Kelly, K. M., Reynoso, J. S., Weber, M., Clarkin, J. F., \& Kernberg, O. F. (2006). Change in attachment patterns and reflective function in a randomized control trial of transference-focused psychotherapy for borderline personality disorder. Journal of Consulting and Clinical Psychology, 74, 1027-1040.

Levy, K.N. (2012). The many complexities in treating and studying narcissism. Pragmatic Case Studies in Psychotherapy, 8(3), Article 3, 216-235. Available: http://hdl.rutgers.edu/1782.1/pcsp_journal

McWilliams, N. (2004). Psychoanalytic psychotherapy: A practitioner's guide. New York: The Guilford Press.

McWilliams, N. (2012). On tone, play, and healing: Commentary on Riordan's case studies. Pragmatic Case Studies in Psychotherapy, 8(3), Article 2, 204-215. Available: http://hdl.rutgers.edu/1782.1/pcsp_journal 
Messer, S.B. (2011). Theory development via single cases: A case study of the therapeutic relationship in psychodynamic therapy. Pragmatic Case Studies in Psychotherapy, 7(4), Article 2, 440-448. Available: http://hdl.rutgers.edu/1782.1/pcsp_journal

Mitchell, S.A. (1988). Relational concepts on psychoanalysis: An integration. Cambridge, MA: Harvard University Press.

Norcross, J. C. (Ed.) (2011). Psychotherapy relationships that work: Evidence-based responsiveness, 2nd ed. New York: Oxford University Press.

Riordan, R.W. (2012). The management of narcissistic vulnerability: Three case studies guided by Stephen Mitchell's integrated treatment model. Pragmatic Case Studies in Psychotherapy, 8(3), Article 1, 150-203. Available: http://hdl.rutgers.edu/1782.1/pcsp_journal 